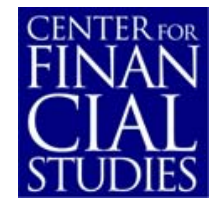

No. $2008 / 54$

Corporate Insurance Design

with Multiple Risks and Moral Hazard

Christian Laux 


\section{Center for Financial Studies}

The Center for Financial Studies is a nonprofit research organization, supported by an association of more than 120 banks, insurance companies, industrial corporations and public institutions. Established in 1968 and closely affiliated with the University of Frankfurt, it provides a strong link between the financial community and academia.

The CFS Working Paper Series presents the result of scientific research on selected topics in the field of money, banking and finance. The authors were either participants in the Center's Research Fellow Program or members of one of the Center's Research Projects.

If you would like to know more about the Center for Financial Studies, please let us know of your interest.

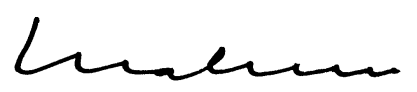

Prof. Dr. Jan Pieter Krahnen

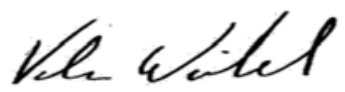

Prof. Volker Wieland, Ph.D. 


\title{
Corporate Insurance Design with Multiple Risks and Moral Hazard*
}

\author{
Christian Laux ${ }^{1}$
}

November, 2008

\begin{abstract}
:
The paper provides novel insights on the effect of a firm's risk management objective on the optimal design of risk transfer instruments. I analyze the interrelation between the structure of the optimal insurance contract and the firm's objective to minimize the required equity it has to hold to accommodate losses in the presence of multiple risks and moral hazard. In contrast to the case of risk aversion and moral hazard, the optimal insurance contract involves a joint deductible on aggregate losses in the present setting.
\end{abstract}

JEL Classification: G22, D82

Keywords: Multiline Insurance, Umbrella Policies, Integrated Risk Management, Deductible Insurance. 


\section{Introduction}

Little is known about the interrelation between risk bundling, the structure of the risk retention, and alternative risk management objectives that may be important for firms. This paper provides new insights into this issue. The optimal structure of risk transfer depends on the interrelation between the risk management motive and the cost of risk management. For two reasons, the interrelation is particularly important for firms. First, different firms may focus on different risk management objectives. Second, firms are in principle quite flexible to use innovative risk transfer instruments.

Much of the insurance literature focuses on risk aversion as the motive for risk transfer, and premium loading, moral hazard, and adverse selection as reasons for why full insurance coverage may not be optimal. An important result in the insurance literature is that, with proportional loading, an insurance contract with a common deductible for aggregate losses is optimal for risk averse policyholders (Arrow, 1963; Raviv, 1979; Gollier and Schlesinger, 1995). No such robust result can be obtained in the case of risk aversion and moral hazard or adverse selection. Holmstrom (1979) shows that under certain conditions a deductible contract on a singe risk can be optimal with moral hazard. However, a standard deductible contract is generally not optimal for risk averse policyholders in the presence of moral hazard.

A main reason for why firms engage in risk management, as discussed in the literature, are deadweight costs of raising and holding capital. Froot et al. (1993) show that convex costs of raising capital to cover losses ex post can induce a firm to act as if it were risk averse. However, raising capital ex post is only one way to deal with risk. Because of regulation, bankruptcy costs, and adverse effects of a debt overhang problem, a firm may ex ante choose a level of equity that is sufficiently high to cover potential losses. Accommodating losses by increasing the firm's equity also involves a cost because of tax disadvantages and information and incentive problems. Reducing the required ex ante equity to accommodate losses is another important risk transfer motive for corporations (e.g., Merton, 2005).

In this paper I focus on the cost of accommodating risk as the risk management motive. The firm faces two independent risks, which may result in a loss or not. Investment in loss 
control reduces the loss probability for each risk, but is unobservable by outsiders. The resulting moral hazard problem is the reason for why the firm may retain some risk. I show that an insurance policy that jointly covers both risks and involves a common aggregate deductible minimizes the required ex ante capital to cover the retained losses subject to the firm's incentive constraints. Thus, a joint deductible is optimal even in the case of moral hazard if the firm's risk management objective is to reduce the cost of accommodating losses.

The recent years have witnessed an increasing development of new contracts, instruments, and solutions to transfer risk. A common characteristic of some of these instruments is that they bundle risk exposures. For example, multiline insurance or umbrella policies bundle different risk exposures to be covered by one insurance contract with a common aggregate deductible and policy limit. The first contracts of this type combined property and casualty risks, but more and more multiline products have been developed. The virtue of multiline insurance is much debated. To address this issue, we have to better understand how the products should be designed and how the design relates to the risk management objective and the cost of risk transfer. The present paper provides a further step towards this understanding.

This paper is related to the work by Fluet and Pannequin (1997) and Breuer (2005). They analyze the optimal insurance structure with multiple risks in the case of adverse selection and moral hazard respectively. In their work the motive for risk management stems from risk aversion. Although a comprehensive contract that takes into account all risks is optimal, the optimal contract does not resemble a contract with a joint deductible on aggregate losses. In a setting similar to that analyzed by Breuer (2005), I show that a joint deductible is optimal if the risk management objective is to accommodate losses by holding costly equity.

As a reference case I also analyze the case of proportional loading if the firm's objective is to accommodate losses. The finding that a joint deductible is optimal in this case resembles the work by Shimpi (2001), Harrington et al. (2002), and Meulbroek (2002). Laux (2001) shows that it can be optimal to combine projects to be managed by one manager in the presence of moral hazard. In this work the manager is risk neutral and protected by limited 
liability. The objective is to minimize the expected wage payment subject to the manager's incentive constraints.

There is a large literature that discusses the benefits of pooling and tranching of risks in banking and securitization. A main benefit of risk pooling is that is allows to carve out less risky claims, which is beneficial if verifying the losses (payoffs) is costly or if there is asymmetric information between market participants (e.g., Diamond, 1984; Gorton and Pennacchi, 1990; DeMarzo, 2005). In the current paper the focus is on moral hazard and the benefit of pooling risks is that it allows a more even retention in different loss states, which reduces the required level of equity to cover the retained losses. Nicolò and Pelizzon (2008) consider a similar setting to analyze the optimal structure of credit derivatives and the optimality of bundling credit risk. Their focus is on the role of regulation and opaque markets.

In the next section I introduce the setting. In Section 3 I discuss the role of bundling to reduce transaction costs when insurance contracts are associated with loading. In Section 4 I analyze the optimal retention structure and the role of bundling in the presence of moral hazard problems. I conclude in Section 5. All proofs are in the appendix.

\section{The Setting}

A firm has two identical and uncorrelated risks. For example, a firm may have two production plants, which may be destroyed by a fire. Each risk can result in a loss $x$ with probability $p \in(0,1)$. If the firm invests $c$ in loss control, this risk's loss probability is $p_{l}$, without investment in loss control, the loss probability is $p_{h}>p_{l}$. The firm's total loss is given by $L \in\{2 x, x, 0\}$, with $\operatorname{Pr}(2 x)=p_{i} p_{j}, \operatorname{Pr}(x)=p_{i}\left(1-p_{j}\right)+p_{j}\left(1-p_{i}\right)$, and $\operatorname{Pr}(0)=\left(1-p_{i}\right)\left(1-p_{j}\right)$, where $p_{i}, p_{j} \in\left\{p_{h}, p_{l}\right\}$ are determined by the firm's investment in loss prevention for each risk. Investment in loss prevention is efficient, but unobservable.

The firm is risk neutral. However, because of frictional costs of retaining and transferring risks and potential incentive problems, the firm faces a non-trivial problem when deciding 
how to deal with risks. One alternative is to obtain insurance coverage.

Insurance coverage. In the case of a fire in a production plant, the firm may insure each plant separately. Alternatively, the firm can obtain a multiline or umbrella policy for both plants or transfer the risks to a captive insurance company that reinsures the aggregate risk using a stop-loss policy. Thus, the firm can choose between separate or joint insurance.

Let $I_{L} \in\left\{I_{2}, I_{1}\right\}$ be the total amount that the firm receives from an insurer in the case of a loss of size $2 x$ and $x$, respectively. Given insurance coverage $I_{L}$, the firm's retention is $R_{L}=L-I_{L}$ if a loss of size $L$ occurs. I follow the insurance literature in assuming that the insurance coverage and the retention are non-negative and nondecreasing so that the firm has no incentives to hide or fraudulently cause losses. In the current setting, the assumption implies that $0 \leq I_{1}$ and $0 \leq \Delta I \leq \Delta L$.

The premium for insurance coverage is given by $P=(1+\alpha) E\left[I_{L}\right]$ where $\alpha \geq 0$ is a proportional loading factor. Premium loading can be one reason for the firm to decide to retain some of the risk. Moreover, if the firm fully insures both risks, it has no incentives to invest in reducing the loss probabilities. Insurers anticipate the negative incentives and the firm must bear the consequences in the form of a higher premium for the insurance policy. To retain incentives to invest in loss control, the firm has to participate in the loss.

However, retaining risk is also costly as the firm either has to raise capital ex post to finance the losses that are not covered by insurance or it has to increase its equity to accommodate the uninsured losses. I focus on the objective of accommodating losses and derive the structure of the insurance contract that minimizes the cost of accommodation subject to the firm retaining incentives to invest in loss control. Deriving the level of required capital that is necessary to retain incentives to invest in loss control is an important step in the firm's overall risk management decision. If the cost of holding the necessary equity is too high, the firm might find it optimal to transfer the total risk despite the moral hazard conflict. 
Accommodating the loss. The firm can accommodate losses by increasing its equity. Indeed, as in the case of a bank, the firm may be required by regulation to hold equity to cover potential losses. Moreover, holding equity may be preferred to uncovered losses because of a potential debt overhang problem after large uncovered losses. Holding equity involves deadweight costs because of a tax disadvantage of equity and adverse selection or information problems. The level of required equity increases in the sum of the insurance premium $P$ and the maximum loss that the firm retains, which is given by $R_{2}$ since the retention is nondecreasing. Thus, the frictional cost of equity is an increasing function of $P+R_{2}$, which I define as $\gamma\left(P+R_{2}\right)$. For ease of exposition, I ignore other factors that determine the required equity and assume that $\gamma(y)>0$ and $\gamma^{\prime}(y)>0$ for $y \equiv P+R_{2}>0$ and that $\gamma(0)=0$. The firm's objective is to minimize the total (frictional) cost of risk:

$$
\min _{R_{1}, R_{2}} \alpha E\left[L-R_{L}\right]+\gamma\left(P+R_{2}\right)
$$

with $P=(1+\alpha) E\left[L-R_{L}\right]$.

\section{Reducing Transaction Costs}

As a benchmark case, I assume that there is no moral hazard problem and that the cost of accommodating losses is convex. That is, the firm can commit to the optimal level of loss control and $\gamma^{\prime \prime}(y)>0$. With proportional loading and risk averse individuals, the optimal insurance contract is a policy with a common deductible for aggregate losses (Arrow, 1963; Raviv, 1979; Gollier and Schlesinger 1995). In the following I show that a common deductible for aggregate losses is also optimal if the firm's objective is to minimize the transaction costs of risk transfer stemming from loading and the cost of accommodating losses. (See also Shimpi, 2001, Harrington et al., 2002, and Meulbroek, 2002.)

With separate insurance, each contract specifies a level of retention for the underlying risk. Because of symmetry, the same retention $R^{S}$ is chosen for each risk so that $R_{1}=R^{S}$ and $R_{2}=2 R^{S}$. Thus, with separate insurance, the choice of $R_{1}$ determines $R_{2}$. 
If the two risks are jointly insured, $R_{2}$ and $R_{1}$ can be chosen individually to minimize the total cost of risk.

Proposition 1 (i) It is optimal to choose a contract with a joint deductible on aggregate losses. (ii) The optimal joint deductible, $D^{J}$, is higher than the total retention with separate insurance if $D^{J}<x$.

The optimization problem (1) implies that $R_{1}=\min \left\{R_{2}, x\right\}$. Assume that $R_{1}<$ $\min \left\{R_{2}, x\right\}$ instead, then $P$ decreases if $R_{1}$ is increased to $R_{1}=\min \left\{R_{2}, x\right\}$; thereby, the firm reduces the loading as well as the frictional cost of equity. The optimal retention structure can be implemented through an insurance contract that jointly covers both losses with a joint deductible $D^{J}$ so that $R_{2}=D^{J}$ and $R_{1}=\min \left\{x, D^{J}\right\}$.

An insurance contract that jointly covers both losses and has a deductible on the aggregate loss reduces the total costs of risk in the presence of loading and frictional costs of accommodation. The advantage of bundling risks in one contract is to overcome the constraint $R_{2}=2 R_{1}$ with separate insurance. This allows for a more efficient use of the capital held to bear losses. If the firm has to hold sufficient capital to cover losses up to $2 R^{S}$, there is excess capacity to bear losses if only one loss occurs in the case of separate insurance, as in this case the firm only bears $R^{S}$. Thus, when there is (exactly) one loss, the firm retains less risk than it is able and willing to accommodate: the firm is overinsured in the sense that it buys more insurance coverage than is optimal. Increasing the retention in the one-loss case, i.e., increasing $R_{1}$ while holding $R_{2}$ fixed, reduces the expected indemnity payment, and therefore the loading associated with insurance and the frictional costs of accommodating losses.

The firm trades off the frictional cost of accommodation and premium loading when choosing the level of total retention. For a given level of capital, the marginal cost of capital is identical under joint and separate insurance. However, joint insurance uses capital more efficiently (in the one loss case) and reduces the insurance premium, which reduces the marginal cost of accommodation for a given maximum total retention. Moreover, an increase 
in the total deductible by one unit always reduces the insurance coverage by one unit in the two-loss state. The effect of an increase in the total retention by one unit in the one loss state differs: with joint insurance, the insurance coverage in the one-loss state decreases by one unit if $D^{J}<x$, but it has no effect if $D^{J}>x$; with separate insurance, the insurance coverage in the one loss state decreases by one half (if the retention is equally split between both contracts).

If the cost of accommodation is high or if the premium loading of insurance coverage is low, the firm will choose a low deductible and $D^{J}<x$. With joint insurance, each unit of capital held can be used to reduce the insurance coverage for every possible loss state. In this case, a higher deductible is optimal than under separate insurance. In contrast, if the cost of accommodation is low or if the premium loading is high, the deductible $D^{J}$ may exceed $x$. In this case, there are two effects that may result in a total deductible that is higher or lower for joint insurance than for separate insurance. First, with joint insurance, reducing the total deductible reduces only the insurance coverage when both losses are realized, but not in the one-loss case (as with separate insurance). Therefore, reducing the total deductible has a lower effect on the total insurance premium. For that reason, $D^{J}$ may be lower than $2 R^{S}$. Second, for the same level of total retention, the premium is lower for joint insurance than for separate insurance. This reduces the marginal cost of accommodation for a given level of total deductible and makes a higher deductible optimal. Whether $D^{J}$ is higher or lower than $2 R^{S}$ depends on whether the second or first effect dominates.

Continuous losses. The optimality of a joint deductible carries forward to the case of continuous losses. I show that a deductible is optimal in the single risk case. The optimality of a deductible on the aggregate risk then follows directly from the discussion above.

I assume that the loss $x$ is a random variable with $x \in[\underline{x}, \bar{x}]$. A loss still occurs with probability $p$ and, conditional on a loss, the distribution of $x$ is $g(x) . I(x)$ is the total amount that the firm receives from an insurer in the case of a loss of $x$, and $R(x)=x-I(x)$ is the firm's retention. In analogy to the discrete case, I assume that $0 \leq R(x)$ and $0 \leq R^{\prime}(x) \leq 1$ 
for all $x \in[\underline{x}, \bar{x}]$ to assure that the firm has no incentives to hide or fraudulently cause losses. For ease of exposition, I denote $R(x)$ by $R_{x}$.

The firm's objective is to minimize the total frictional cost of risk, $\alpha E\left[L-R_{L}\right]+\gamma\left(P+R_{\bar{x}}\right)$ where $R_{\bar{x}}$ is the maximum retention since $R^{\prime}(x) \geq 0$. The optimal insurance contract implies $R_{x}=\min \left\{x, R_{\bar{x}}\right\}$ for all $x \in[\underline{x}, \bar{x}]$. Assume $R_{x}<\min \left\{x, R_{\bar{x}}\right\}$, then the insurance premium can be reduced by increasing $R_{x}$ to $\min \left\{x, R_{\bar{x}}\right\}$. This reduces the loading and the frictional cost of accommodation. The retention structure can be implemented through an insurance contract with a deductible $D$ so that $R_{x}=\min \{x, D\}$.

Accommodation versus uncovered losses (risk aversion). Although, with proportional loading, a joint deductible is optimal for both risk management motives, the reasons differ. In the case of accommodation, the benefit of a joint deductible stems from a more efficient use of a given level of capital (that is increasing in $P+R_{2}$ ). In the case of uncovered losses (risk aversion), the benefit stems from the convex cost of raising capital (concave utility), which makes it optimal to choose a retention structure where the marginal cost of raising the necessary capital to cover the retention ex post is equal to the proportional loading factor $\alpha$ in all states. Thus, $R_{1}=R_{2}$ unless the constraint $R_{1} \leq x$ is binding: given the convex cost of uncovered losses (concave utility), it is optimal to reduce the volatility of the retention; i.e., it is optimal to reduce the difference between $R_{2}$ and $R_{1}$. This is achieved through a joint deductible.

The different rationale for a joint deductible in both cases can also be observed when considering the effect of joint insurance coverage on the total level of risk that the firm optimally retains. In the case of uncovered losses (risk aversion), the firm's total retention with joint insurance is always lower than with separate insurance. The reason is that the expected marginal costs of capital (expected utilities) differ for joint and separate insurance. The deductible in the one-loss case is lower with separate insurance. Therefore, the expected marginal frictional cost of the uncovered retention (marginal utility) is also lower, which, given proportional loading, increases the optimal level of the deductible for each risk, 
resulting in a higher total retention.

\section{Improving the Trade-Off Between Risk Transfer and Incentives}

In this section I analyze the effect of moral hazard on the optimal retention structure with joint insurance. Therefore, I drop again the assumption that the firm can commit to loss control. To focus on the incentive problem and, in particular, on the interaction between the optimal incentive-compatible retention and the cost of accommodating risk, I assume zero loading $(\alpha=0)$. Thus, without the incentive problem, it would be optimal for the firm to fully insure both risks. Because of the incentive problem, the firm may find it optimal to retain some risk, and its objective is to choose the retention structure that minimizes the frictional cost of accommodating losses subject to the firm's incentive constraints. With zero loading, (1) is equivalent to minimizing $P+R_{2}$. The firm's optimization problem is given by

$$
\min _{R_{1}, R_{2}} P+R_{2}
$$

subject to

$$
\begin{gathered}
p_{l}^{2} R_{2}+2 p_{l}\left(1-p_{l}\right) R_{1}+2 c \leq p_{h} p_{l} R_{2}+\left(p_{h}\left(1-p_{l}\right)+p_{l}\left(1-p_{h}\right)\right) R_{1}+c \\
p_{l}^{2} R_{2}+2 p_{l}\left(1-p_{l}\right) R_{1}+2 c \leq p_{h}^{2} R_{2}+2 p_{h}\left(1-p_{h}\right) R_{1} \\
P=E[L]-p_{l}^{2} R_{2}-2\left(1-p_{l}\right) p_{l} R_{1}
\end{gathered}
$$

The firm's incentive constraints are given by (IC1) and (IC2). (IC1) assures that the firm does not shirk on one of the risks and (IC2) assures that the firm does not shirk on both risks. Because of symmetry, it is not necessary to distinguish between the two individual risks; (IC1) captures both risks in the sense that if the firm has an incentive to shirk on (exactly) one risk, it is indifferent between the two, and if it has no incentive to shirk only on risk $i$, it has no incentive to shirk only on $j \neq i$. The frictional cost of capital does not enter the incentive constraints because, for a given level of capital, the frictional cost of accommodating risk is given and not affected by the loss realization. 
Separate insurance. With separate insurance, $R_{2}=2 R_{1}$. Substituting $P$ and $R_{2}=2 R_{1}$ into the optimization problem (2) and rearranging terms yields

$$
\min _{R_{1}} E[L]+2\left(1-p_{l}\right) R_{1}
$$

subject to

$$
p_{l} R_{1}+c \leq p_{h} R_{1}
$$

Because of symmetry, the incentive-compatible retention structures for both risks are identical, and (IC1) and (IC2) converge to $\left(\mathrm{IC}^{S}\right)$. It directly follows that it is optimal for the firm to minimize $R_{1}$ subject to the incentive constraint. Thus, the incentive constraint is binding and the optimal retention is

$$
R^{*}=\frac{c}{p_{h}-p_{l}}
$$

Joint insurance. With a single policy, $R_{1}$ and $R_{2}$ are chosen individually to minimize $P+R_{2}$ subject to (IC1) and (IC2):

$$
\begin{gathered}
c \leq\left(p_{h} p_{l}-p_{l}^{2}\right) R_{2}+\left(p_{h}-p_{l}\right)\left(1-2 p_{l}\right) R_{1} \\
c \leq 0.5\left(p_{h}^{2}-p_{l}^{2}\right) R_{2}+\left(p_{h}-p_{l}\right)\left(1-p_{h}-p_{l}\right) R_{1} .
\end{gathered}
$$

Absent the incentive constraints, full insurance is optimal for the firm so that the incentive constraints place a lower bound on the retention. I proceed in two steps. First, I analyze the structure of the incentive-compatible insurance contract that minimizes $R_{2}$. Second, I derive the optimal incentive-compatible retention that minimizes $P+R_{2}$.

Lemma 1 The incentive-compatible joint contract that minimizes $R_{2}$ is characterized by:

(a) A common aggregate deductible if $p_{h}+p_{l}<1$.

(b) A common aggregate policy limit if $p_{l}>0.5$.

(c) The same retention structure as separate insurance if $p_{h}+p_{l} \geq 1$ and $p_{l}<0.5$.

In case (a) the probability of incurring exactly one loss is higher if the firm shirks, and chooses either one or no investment in loss prevention, than if it invests in loss prevention for 
both risks. Therefore, participating in $L=x$ has a positive incentive effect. Increasing $R_{1}$ allows to reduce $R_{2}$. Minimizing $R_{2}$ implies that $R_{1}=\min \left\{x, R_{2}\right\}$ and that (IC2) is binding. In contrast, the probability of incurring exactly one loss is higher if the firm does not shirk in case (b). As a consequence, the incentive effect of participating in $L=x$ is negative and it is optimal to reduce the retained risk in this state to zero. This allows to reduce $R_{2}$. In case (c) the joint retention structure resembles the one with separate insurance and it is not possible to reduce $R_{2}$.

Substituting $P=p_{l}^{2}\left(2 x-R_{2}\right)+2 p_{l}\left(1-p_{l}\right)\left(x-R_{1}\right)$ into the objective function and rearranging terms yields

$$
\min _{R_{1}, R_{2}} E[L]-2 p_{l}\left(1-p_{l}\right) R_{1}+\left(1-p_{l}^{2}\right) R_{2}
$$

Thus, the incentive-compatible retention that minimizes $R_{2}$ may not coincide with the incentive compatible retention that minimizes $P+R_{2}$.

While $P+R_{2}$ increases in $R_{2}$, it decreases in $R_{1}$. Thus, the overall effect in (b), which requires to reduce $R_{1}$ in order to reduce $R_{2}$, is unclear. Indeed, it may be optimal to increase $R_{1}$ (compared to separate insurance) even if incentive compatibility requires to also increase $R_{2}$. The same would then also be true in (c).

Proposition 2 (i) The incentive-compatible contract that minimizes $P+R_{2}$ is a contract with a joint deductible on aggregate losses. (ii) The optimal joint deductible is lower (higher) than the total retention with separate insurance if $p_{h}+p_{l}<1\left(p_{h}+p_{l} \geq 1\right)$.

The optimality of a contract with a joint deductible is straightforward in case (a), where it stems from higher incentives, which allows to reduce $R_{2}$. In cases (b) and (c), the benefit of a deductible contract stems from a reduction in the insurance premium. While increasing $R_{1}$ requires to also increase $R_{2}$ to assure incentive compatibility, the increase in $R_{2}$ is overcompensated by the reduction of the premium. Again, the advantage of multiline insurance stems from reducing the difference between $R_{2}$ and $R_{1}$ and the reduction in the insurance premium. 
Part (ii) directly follows from (i) and the discussion above. If $p_{h}+p_{l}<1$, increasing $R_{1}$ to $R_{1}=\min \left\{L, R_{2}\right\}$ allows to reduce $R_{2}$ and therefore the joint deductible. If $p_{h}+p_{l} \geq 1$, increasing $R_{1}$ to $R_{1}=\min \left\{L, R_{2}\right\}$ (which is optimal as stated in part (i)) requires to also increase $R_{2}$.

One loss prevention program for both risks. The discussion carries forward to the case where one effort affects both probabilities. That is, the firm can choose $p_{i}=p_{j}=p_{h}$ at zero costs or $p_{i}=p_{j}=p_{l}$ at costs $\hat{c}=2 c$. The analysis is similar to the one with two separate effort choices for the two risks and Proposition 3 continues to hold. The only difference is that (IC2) is now the only incentive constraint. (IC1) is no longer relevant since the choice $p_{i}=p_{h}$ and $p_{j}=p_{l}$ is no longer an option.

Continuous losses and pure loss avoidance. The loss $x$ is a random variable with $x \in[\underline{x}, \bar{x}]$. As Holmstrom (1979), I assume that the loss occurs with probability $p_{i} \in\left\{p_{l}, p_{h}\right\}$ and, conditional on a loss, the distribution of $x$ is $g(x)$. Therefore, loss control only affects the probability of a loss, but not the conditional distribution. In this case, only the expected retention in the case of a loss matters for incentives. Since the firm has to hold equity to cover the maximum retained loss and premium, it is optimal to choose a contract with a deductible. Thus, for the case considered by Holmstrom (1979), the discussion above directly implies that it is optimal to choose an insurance contract that covers both risks with a deductible on the aggregate loss if the firm's objective is to minimize the cost of accommodation. In contrast, as shown by Breuer (2005), a deductible on aggregate losses is not optimal if the risk management motive stems from risk aversion.

\section{Conclusion}

I consider a firm that wants to accommodate losses by holding equity. Equity is associated with frictional costs of raising and holding it. One way to reduce the required equity is to transfer potential losses through insurance. Because of transaction costs of risk transfer 
or moral hazard problems, it may not be optimal to completely transfer potential losses. Therefore, the firm has to decide on the optimal retention structure when transferring risks. In the case of frictional costs of risk transfer, it is optimal to choose a contract with a joint deductible on aggregate losses: e.g., a multiline insurance policy with a deductible on aggregate losses. In the setting considered in this paper, this contract is also optimal if the reason for retaining risk stems from moral hazard.

I assumed that the firm chooses the level of loss control and then losses are realized (or not). That is, there is no interim moral hazard problem where the firm can adjust the level of care in response to observing interim loss realizations. With interim moral hazard there is a cost of a joint deductible: if the firm realizes a loss that exceeds the deductible, it has no longer an incentive to bear the cost of reducing the loss probability on its other risks that are covered by the same policy. To what extent interim moral hazard is a potential problem depends on the type of loss control. The interim moral hazard problem is low if the level of loss control is difficult to change (e.g., organizational procedures that reduce the loss probability) or if losses are realized long after the investment in loss control (e.g., care in product design).

\section{Appendix}

Proof of Proposition 1. (i) The first part directly follows from the discussion after Proposition 1.

(ii) Since there is no commitment problem, I drop the index from the loss probability; each loss occurs with probability $p$. Substituting $E\left[R_{2}\right]=p^{2} R_{2}+2(1-p) p R_{1}$ in (1), yields $\alpha E[L]-\alpha\left(p^{2} R_{2}+2(1-p) p R_{1}\right)+\gamma\left((1+\alpha)\left(E[L]-\left(p^{2} R_{2}+2(1-p) p R_{1}\right)\right)+R_{2}\right)$.

With separate insurance, the optimal retention $R^{S}$ minimizes $\alpha E[L]-2 \alpha p R^{S}+\gamma((1+$ $\left.\alpha)\left(E[L]-2 p R^{S}\right)+2 R^{S}\right)$. Therefore $R^{S}$ is given by the first order condition $-2 \alpha p+\gamma^{\prime}((1+$ $\left.\alpha)\left(E[L]-2 p R^{S}\right)+2 R^{S}\right)(-(1+\alpha) 2 p+2)=0$. Rearranging terms yields $\alpha p /(1-(1+\alpha) p)=$ $\gamma^{\prime}\left((1+\alpha) E[L]+(1-(1+\alpha) p) 2 R^{S}\right)$. 
With joint insurance, the deductible minimizes $\alpha E[L]-\alpha\left(p^{2} D^{J}+2(1-p) p \min \left\{D^{J}, x\right\}\right)+$ $\gamma\left((1+\alpha)\left(E[L]-\left(p^{2} D^{J}+2(1-p) p \min \left\{D^{J}, x\right\}\right)\right)+D^{J}\right)$.

For $D^{J}<x$, the first order condition for the optimal $D^{J}$ is $-\alpha(2-p) p+\gamma^{\prime}((1+\alpha)(E[L]-$ $\left.\left.(2-p) p D^{J}\right)+D^{J}\right)(1-(1+\alpha)(2-p) p)=0$. Rearranging terms yields $\alpha(2-p) p /(1-(1+$ $\left.\alpha)\left(2 p-p^{2}\right)\right)=\gamma^{\prime}\left((1+\alpha)\left(E[L]-(2-p) p D^{J}\right)+D^{J}\right)$.

The left-hand side of the first order condition with separate insurance is lower than the left-hand side of the first order condition with joint insurance: $\alpha p /(1-(1+\alpha) p)<$ $\alpha(2-p) p /\left(1-(1+\alpha)\left(2 p-p^{2}\right)\right)$. Rearranging terms yields $1<(2-p)$. Moreover, $1-(1+\alpha) p>$ $1-(1+\alpha)(2-p) p$ since $p<1$. Since the cost of accommodation are convex, $2 R^{S}<D^{J}$.

For $D^{J}>x$, the first order condition for the optimal $D^{J}$ is $-\alpha p^{2}+\gamma^{\prime}((1+\alpha)(E[L]-$ $\left.\left.\left(p^{2} D^{J}+2(1-p) p x\right)\right)+D^{J}\right)\left(1-(1+\alpha) p^{2}\right)=0$. Rearranging terms yields $\alpha p^{2} /\left(1-(1+\alpha) p^{2}\right)=$ $\gamma^{\prime}\left((1+\alpha)\left(E[L]-\left(p^{2} D^{J}+2(1-p) p x\right)\right)+D^{J}\right)$.

The left-hand side of the first order condition with separate insurance is higher than the left-hand side of the first order condition with joint insurance: $\alpha p /(1-(1+\alpha) p)>$ $\alpha p^{2} /\left(1-(1+\alpha) p^{2}\right)$. Rearranging terms yields $1>p$. Moreover, $(1-(1+\alpha) p) 2 R^{S}>$ $\left.D^{J}-(1+\alpha)\left(p^{2} D^{J}+2(1-p) p x\right)\right)$ for $2 R^{S}=D^{J}>2 x$. Substituting $2 R^{S}=D^{J}$ in the inequality and rearranging terms yields $D^{J}>2 x$. Therefore, $2 R^{S}$ may be higher or lower than $D^{J}$.

Q.E.D.

Proof of Lemma 1. (a) $p_{h}+p_{l}<1$ implies that $\left(p_{h}-p_{l}\right)\left(1-p_{h}-p_{l}\right)>0$. Moreover, $\left(p_{h}-p_{l}\right)\left(1-2 p_{l}\right)>0$ when $p_{l}<0.5$, which is satisfied for $p_{h}+p_{l}<1$. Therefore, both terms are positive and increasing $R_{1}$ allows to reduce $R_{2}$ without violating the incentive constraint. Minimizing $R_{2}$, implies $R_{1}=\min \left\{x, R_{2}\right\}$ subject to (IC1) and (IC2). It is straightforward to check that (IC2) is the binding constraint. The contract can be implemented with a common deductible $D^{J}$ with $R_{2}=D^{J}$ and $R_{1}=\min \left\{x, D^{J}\right\}$.

(b) $p_{l}>0.5$ implies $p_{h}+p_{l}>1$ and therefore, $\left(p_{h}-p_{l}\right)\left(1-2 p_{l}\right)<0$ and $\left(p_{h}-p_{l}\right)(1-$ $\left.p_{h}-p_{l}\right)<0$. Now, it is possible to reduce $R_{2}$ without violating the incentive constraints by simultaneously decreasing $R_{1}$. Minimizing $R_{2}$ implies $R_{1}=0$ and only (IC1) is binding; 
$R_{2}=c /\left[p_{l}\left(p_{h}-p_{l}\right)\right]$. If $c /\left[p_{l}\left(p_{h}-p_{l}\right)\right]>x$, i.e., $R_{2}-R_{1}>x$, the firm would have an incentive to hide the second loss. To assure honest reporting, $R_{2}=R_{1}+x$ and $R_{1}$ is chosen so that (IC1) is binding. The retention structure can be implemented through a common aggregate policy limit $I^{J}$ with $R_{2}=2 x-I^{J}$ and $R_{1}=\max \left\{0, x-I^{J}\right\}$.

(c) If $p_{h}+p_{l} \geq 1$ and $0.5 \leq p_{l}$, it is not possible to relax both constraints by changing $R_{1}$ and it is therefore not possible to reduce $R_{2}$ without violating at least one of the incentive constraints. Hence, $R_{2}^{*}=2 R_{1}^{*}=2 c /\left[p_{h}-p_{l}\right]$ is optimal.

Q.E.D.

Proof of Proposition 2. (i) To derive the optimal retention structure, it is important to know which incentive constraint is binding. For the optimal separate contract, $R_{2}=2 R_{1}$ and (IC1) and (IC2) are both binding. When, starting from the retention structure in the optimal separating contracts, $R_{1}$ and $R_{2}$ are changed in a joint contract, only (IC2) is binding if $d R_{2}<2 d R_{1}$ and therefore $R_{2}<2 R_{1}$. In contrast, only (IC1) is binding if $d R_{2}>2 d R_{1}$ and $R_{2}>2 R_{1}$.

If (IC2) is binding, then $R_{2}$ is given by

$$
R_{2}=\frac{2 c}{\left(p_{h}^{2}-p_{l}^{2}\right)}-\frac{2\left(1-p_{h}-p_{l}\right)}{\left(p_{h}+p_{l}\right)} R_{1}
$$

and $\frac{\partial R_{2}}{\partial R_{1}}=-\frac{2\left(1-p_{h}-p_{l}\right)}{\left(p_{h}+p_{l}\right)}<2$, which implies that $d R_{2}<2 d R_{1}$ if $d R_{1}>0$ and $d R_{2}>2 d R_{1}$ if $d R_{1}<0$.

If (IC1) binding, then $R_{2}$ is given by

$$
R_{2}=\frac{c}{\left(p_{h} p_{l}-p_{l}^{2}\right)}-\frac{\left(1-2 p_{l}\right)}{p_{l}} R_{1}
$$

with $\frac{\partial R_{2}}{\partial R_{1}}=-\frac{\left(1-2 p_{l}\right)}{p_{l}}<2$. Again, $d R_{2}<2 d R_{1}$ if $d R_{1}>0$ and $d R_{2}>2 d R_{1}$ if $d R_{1}<0$.

Therefore, (IC2) is binding if it is optimal to increase $R_{1}$ starting from the optimal separate contract while (IC1) is binding if it is optimal to decrease $R_{1}$.

I first check, whether it is optimal to reduce $R_{1}$. In this case, (IC1) is binding and the objective function is given by $E[L]-2 p_{l}\left(1-p_{l}\right) R_{1}+\left(1-p_{l}^{2}\right)\left[\frac{c}{\left(p_{h} p_{l}-p_{l}^{2}\right)}-\frac{\left(1-2 p_{l}\right)}{p_{l}} R_{1}\right]$. The first order condition for the optimal $R_{1}$ is $-2 p_{l}\left(1-p_{l}\right)-\left(1-p_{l}^{2}\right) \frac{\left(1-2 p_{l}\right)}{p_{l}}$, which is negative since 
$p_{l}<1$. Thus, it would be optimal to increase $R_{1}$. However, in this case (IC2) is the relevant constraint.

I now assume that (IC2) is binding and substitute (A1) in the objective function to obtain $E[L]-2 p_{l}\left(1-p_{l}\right) R_{1}+\left(1-p_{l}^{2}\right)\left[\frac{2 c}{\left(p_{h}^{2}-p_{l}^{2}\right)}-\frac{2\left(1-p_{h}-p_{l}\right)}{\left(p_{h}+p_{l}\right)} R_{1}\right]$. The first order condition for

the optimal $R_{1}$ is $-2 p_{l}\left(1-p_{l}\right)-\left(1-p_{l}^{2}\right)\left[\frac{2\left(1-p_{h}-p_{l}\right)}{\left(p_{h}+p_{l}\right)}\right]<0$ since $p_{h}<1$. Thus, it is optimal to increase $R_{1}$ and to set $R_{1}=\min \left\{x, R_{2}\right\}$.

(ii) The second part of the proposition directly follows from (i) and the discussion in the main text.

\section{References}

[1] Arrow, K.J.: Uncertainty and the Welfare Economics of Medical Care, American Economic Review 53, 1963, 941-973.

[2] Breuer, M.: Multiple Losses, Ex Ante Moral Hazard, and the Implications for Umbrella Policies, Journal of Risk and Insurance 72, 2005, 525-538.

[3] Diamond, D.: Financial Intermediation and Delegated Monitoring, Review of Economic Studies 51, 1984, 393-414.

[4] DeMarzo, P.M.: The Pooling and Tranching of Securities: A Model of Informed Intermediation, Review of Financial Studies 18, 2005, 1-35.

[5] Fluet, C., and F. Pannequin: Complete versus Incomplete Insurance Contracts under Adverse Selection with Multiple Risks, Geneva Papers on Risk and Insurance Theory 22, 1997, 82-101.

[6] Froot, K.A., D.S. Scharfstein, and J.C. Stein: Risk Management: Coordinating Corporate Investment and Financing Policies, Journal of Finance 48, 1993, 1629-1658.

[7] Gollier, C., and H. Schlesinger: Second-Best Insurance Contract Design in an Incomplete Market, Scandinavian Journal of Economics 97, 1995, 123-135. 
[8] Gorton, G., and G. Pennacchi: Financial Intermediaries and Liquidity Creation, Journal of Finance 55, 1990, 49-71.

[9] Harrington, S.E., and G. Niehaus, and K.J. Risko: Enterprise Risk Management: The Case of United Grain Growers, Journal of Applied Corporate Finance 14, 2002, 71-81.

[10] Holmstrom, B.: Moral Hazard \& Observability, Bell Journal of Economics 10, 1979, 74-91.

[11] Laux, C.: Limited Liability and Incentive Contracting with Multiple Projects, $R A N D$ Journal of Economics 32, 2001, 514-526.

[12] Merton, R.C.: You Have More Capital than You Think, Harvard Business Review, 2005, $85-94$.

[13] Meulbroek, L.: The Promise and Challenge of Integrated Risk Management, Risk Management and Insurance Review 5, 2002, 56-70.

[14] Nicolò, A., and L. Pelizzon: Credit Derivatives, Capital Requirements and Opaque OTC Markets, Journal of Financial Intermediation 17, 444-463, 2008.

[15] Raviv, A.: The Design of an Optimal Insurance Policy, American Economic Review 69, 1979, 84-96.

[16] Shimpi, P.: Multi-Line and Multi-Trigger Products, in: Integrating Corporate Risk Management, P. Shimpi (Ed.), Texere, New York and London, 2001, 101-124. 


\section{CFS Working Paper Series:}

\begin{tabular}{|c|c|c|}
\hline No. & Author(s) & Title \\
\hline $2008 / 53$ & Gunther Wuyts & $\begin{array}{l}\text { The Impact of Liquidity Shocks Through the Limit } \\
\text { Order Book }\end{array}$ \\
\hline $2008 / 52$ & $\begin{array}{l}\text { Azi Ben-Rephael } \\
\text { Ohad Kadan } \\
\text { Avi Wohl }\end{array}$ & The Diminisching Liquidity Premium \\
\hline $2008 / 51$ & Otmar Issing & The Euro - A Currency without a State \\
\hline $2008 / 50$ & $\begin{array}{l}\text { Joachim G. Grammig } \\
\text { Franziska J. Peter }\end{array}$ & $\begin{array}{l}\text { International Price Discovery in the Presence of } \\
\text { Microstructure Noise }\end{array}$ \\
\hline $2008 / 49$ & Markus Gsell & $\begin{array}{l}\text { Assessing the Impact of Algorithmic Trading on } \\
\text { Markets: A Simulation Approach }\end{array}$ \\
\hline $2008 / 48$ & $\begin{array}{l}\text { Stefan Frey } \\
\text { Patrik Sandas }\end{array}$ & $\begin{array}{l}\text { The Impact of Hidden Liquidity in Limit Order } \\
\text { Books }\end{array}$ \\
\hline $2008 / 47$ & $\begin{array}{l}\text { Albert J. Menkveld } \\
\text { Asani Sarkar } \\
\text { Michel van der Welt }\end{array}$ & $\begin{array}{l}\text { Customer Flow, Intermediaries, and the Discovery } \\
\text { of the Equilibrium Riskfree Rate }\end{array}$ \\
\hline $2008 / 46$ & Mark Van Achter & $\begin{array}{l}\text { A Dynamic Limit Order Market with Diversity in } \\
\text { Trading Horizons }\end{array}$ \\
\hline $2008 / 45$ & $\begin{array}{l}\text { Michael S. Pagano } \\
\text { Lin Peng } \\
\text { Robert A. Schwartz }\end{array}$ & $\begin{array}{l}\text { The Quality of Price Formation at Market } \\
\text { Openings and Closings: Evidence from the Nasdaq } \\
\text { Stock Market }\end{array}$ \\
\hline $2008 / 44$ & $\begin{array}{l}\text { David Reiffen } \\
\text { Michel Robe }\end{array}$ & $\begin{array}{l}\text { Demutualization and Enforcement Incentives at } \\
\text { Self-regulatory Financial Exchanges }\end{array}$ \\
\hline
\end{tabular}

Copies of working papers can be downloaded at http://www.ifk-cfs.de 